\title{
AVALIAÇÃO DO DESEMPENHO DE RESÍDUO DE ALUMINATO DE SÓDIO COMO COAGULANTE
}

\author{
EVALUATION OF THE PERFORMANCE OF SODIUM ALUMINATE WASTE AS \\ COAGULANT \\ Andrea Santos Liu ${ }^{1}$ \\ Gabrielle Napoleão Oliveira ${ }^{2}$ \\ Carolina Inácio Portela ${ }^{3}$ \\ Liu Yao $\mathrm{Cho}^{4}$
}

\begin{abstract}
Resumo: O crescimento populacional, acompanhado de um processo de urbanização acelerado, gera inúmeros impactos ambientais, ressaltando-se a crescente produção de resíduos sólidos. $O$ reaproveitamento desses resíduos é fundamental, pois reduz a necessidade de extração de novos recursos naturais, aumenta a vida útil de aterros, minimiza impactos ambientais e traz ganhos econômicos, contribuindo para a sustentabilidade do setor industrial. Com o objetivo de reduzir os impactos provenientes do descarte inadequado de resíduos industriais e avaliar o seu reaproveitamento, no presente trabalho foi realizado um estudo comparativo entre um coagulante convencional e um resíduo de aluminato de sódio, por intermédio de ensaios de Jar Test. Os resultados mostram que a adição de 50,0 ppm do resíduo de aluminato à água residuária promove a remoção de, aproximadamente, 92,0\% das partículas em suspensão no efluente. Além disso, foi observado que o custo do resíduo de aluminato é muito inferior quando comparado com o cloreto férrico convencional. Dessa forma, o presente estudo revelou a possibilidade de readmitir um resíduo, potencialmente perigoso, na cadeia produtiva, economizando matéria prima e também proporcionando uma melhor destinação final para esse resíduo.
\end{abstract}

Palavras-chave: Sustentabilidade; reutilização; coagulante; aluminato de sódio.

Abstract: Population growth accompanied by accelerated urbanization process generates numerous environmental impacts, emphasizing the growing production of solid waste. The reuse of this waste is important because it reduces the extraction of natural resources and extends the life of landfills what minimizes environmental impacts and brings economic gains. It also contributes to the sustainability of industries. In order to reduce the impacts of inappropriate waste disposal it is presented in this paper a comparative study between a conventional coagulant and a sodium aluminate residue through Jar Test trials. The results show that addition of $50.0 \mathrm{ppm}$ aluminate residue to the wastewater, promotes the removal of $92 \%$ of particulate matter in the effluent, what is much cheaper as compared with the use of ferric chloride. Thus, this study revealed the possibility to readmit a potentially hazardous waste in the supply chain, saving raw materials and also providing better disposal for this waste.

Keywords: Sustainability; reuse; coagulant; sodium aluminate.

\footnotetext{
1 Doutora em Engenharia Aeronáutica e Mecânica - Instituto Federal de Educação, Ciência e Tecnologia de São Paulo - IFSP, Brasil. E-mail: aliu@ifsp.edu.br.

2 Graduanda em Licenciatura em Ciências Biológicas pelo Instituto Federal de São Paulo. Instituto Federal de Educação, Ciência e Tecnologia de São Paulo - IFSP, Brasil. E-mail: emaildapink@gmail.com.

${ }^{3}$ Graduanda em Engenharia Ambiental e Sanitária - FEAU - Universidade do Vale do Paraíba, Brasil. E-mail: carol_inacioportela@hotmail.com.

4 Doutor em Química - IP\&D / FEAU - Universidade do Vale do Paraíba, Brasil. E-mail: liu@univap.br.
} 


\section{INTRODUÇÂO}

O crescimento populacional, acompanhado de um processo de urbanização acelerado, gera inúmeros impactos ambientais, dentre os quais, ressalta-se a crescente produção de resíduos sólidos. O manejo inadequado desses resíduos, associado ao excessivo volume produzido, causa problemas de saúde pública, prejuízos econômicos e degradação da qualidade ambiental. (LENARDÃO, 2003).

A Lei 12305/2010 instituiu a Política Nacional de Resíduos Sólidos (PNRS), que estabeleceu uma ordem de prioridade na gestão dos resíduos, que envolve: não geração; redução da quantidade e da toxidade de resíduos a serem gerados; reutilização dos resíduos; reciclagem; tratamento dos resíduos já gerados com o intuito de diminuir o seu volume ou grau de toxidade; e, por fim, a disposição final em aterros sanitários. (BRASIL, 2010).

Visando atender a PNRS, diversos setores industriais tiveram que adotar programas para o gerenciamento adequado de seus resíduos sólidos, priorizando ações que enfatizem a redução na fonte, reutilização e reciclagem, para minimizar os problemas associados com o descarte dos resíduos. (RIBEIRO, 2010).

O reaproveitamento de resíduos, como os de aluminato, evita o descarte inadequado de íons de alumínio $\left(\mathrm{Al}^{+3}\right)$, que causam inúmeros impactos à saúde humana e ao meio ambiente, já que se trata de uma espécie citotóxica e que pode estar relacionada com danos neurológicos e aumento na incidência da doença de Alzheimer (BAIRD, 2002). Além disso, minimiza a necessidade de extração de recursos minerais, como a bauxita, utilizada na produção do coagulante convencional, o sulfato de alumínio.

Vale ressaltar que diversos efluentes industriais, como aqueles provenientes de indústrias cerâmicas, apresentam elevada turbidez (MORUZZI, 2009). Dessa forma, o seu descarte, sem tratamento adequado, pode provocar danos aos corpos hídricos receptores.

Estudos sugerem que a água com elevada turbidez também pode ocasionar problemas do ponto de vista sanitário, já que alguns microrganismos patogênicos podem se alojar nas partículas em suspensão e se proteger da ação de desinfetantes quando a água é captada e submetida ao tratamento em Estações de Tratamento de Água, a ser destinada ao abastecimento público. (VAZ, 2010).

A coagulação consiste no conjunto de ações físicas e químicas entre o agente coagulante e as impurezas presentes na água a ser tratada. Apresenta três fases; (i) formação de espécies hidrolisadas do sal disperso na água; (ii) desestabilização das partículas coloidais presentes no efluente; (iii) agregação dessas partículas, formando os flocos. (SANTOS, 2011).

Desta forma, a adição de um coagulante químico promove o processo de 
coagulação, por intermédio da desestabilização das partículas coloidais presentes na água, as quais deixam de se repelir, permitindo sua posterior agregação, para a formação de flocos. Esses flocos apresentam melhores condições de sedimentabilidade e filtrabilidade, o que facilita a sua remoção do efluente líquido (American Water Works Association, 1989).

Os sais de alumínio e de ferro são agentes coagulantes muito utilizados no tratamento de efluentes, por apresentarem baixo custo e boa eficiência. O sulfato ferroso é utilizado para tratamento de efluentes com pH elevado (entre 8,5 e 11,0), o sulfato férrico no tratamento de efluentes altamente coloridos ou ácidos, sendo efetivo na faixa de $\mathrm{pH}$ entre 5,0 a 11,0, enquanto o cloreto férrico produz bons flocos nessa mesma faixa de $\mathrm{pH}$. Por outro lado, o sulfato de alumínio é usado no tratamento convencional de água para abastecimento público, já o aluminato de sódio, considerado um coagulante básico, é usado como um aditivo para a coagulação secundária de efluentes altamente coloridos. (FREITAS, 2013).

No presente trabalho, resíduos à base de aluminato de sódio foram investigados para atuar como coagulante no tratamento de efluentes, com elevada turbidez e sua performance foi comparada com a do cloreto férrico, um coagulante químico convencional.

\section{EXPERIMENTAL}

A Figura 1 apresenta um fluxograma das etapas envolvidas no desenvolvimento deste trabalho.

Figura 1. Fluxograma das etapas desenvolvidas no trabalho.

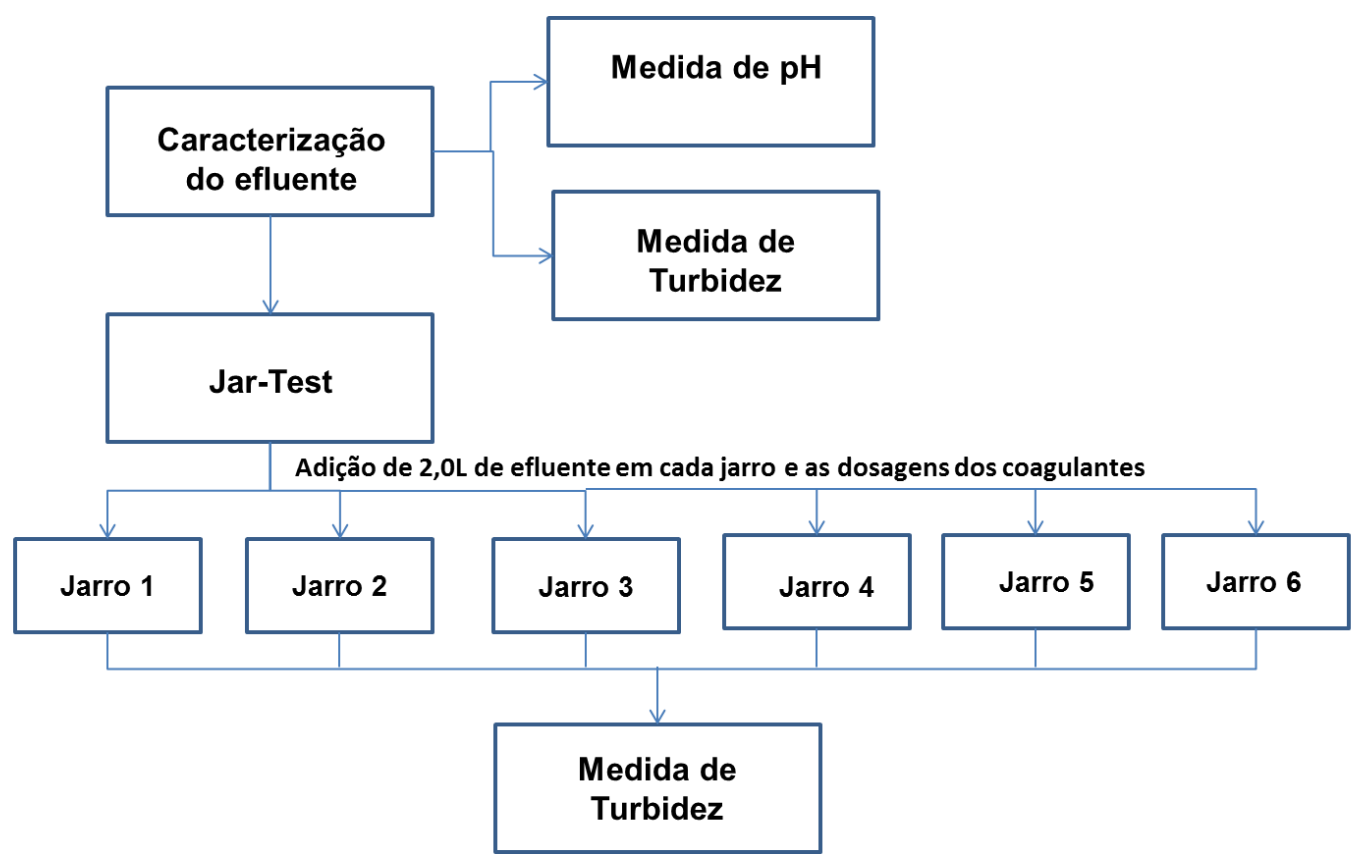

Fonte: Autores. 


\section{REAGENTES, SOLUÇÕES E MATERIAIS}

O resíduo de aluminato de sódio cedido pela empresa B2Blue foi analisado e sua composição é apresentada na Tabela 1. Esse resíduo era constituído por grandes grãos aglomerados e, inicialmente, foi triturado e homogeneizado. Em seguida, foi preparada uma solução aquosa $1 \% \mathrm{~m} / \mathrm{v}$ de aluminato de sódio, presente no resíduo.

Tabela 1. Composição do resíduo industrial utilizado no presente trabalho.

\begin{tabular}{cc}
\hline Componente & Porcentagem (\%) \\
\hline Aluminato de sódio $\left(\mathrm{NaAlO}_{2}\right)$ & $38,27 \%$ \\
Óxido de alumínio $\left(\mathrm{Al}_{2} \mathrm{O}_{3}\right)$ & $52,73 \%$ \\
Óxido de sódio $\left(\mathrm{Na}_{2} \mathrm{O}\right)$ & $9,00 \%$ \\
\hline
\end{tabular}

Para avaliar o desempenho do resíduo de aluminato, como coagulantes no tratamento de águas residuárias, foram realizados ensaios no equipamento Jar Test, modelo JT102-6 - MILAN, constituído por 6 jarros com capacidade de 2,0 L que fornece gradiente de velocidade entre 10 e $2000 \mathrm{~s}^{-1}$. O Jar Test tem sido utilizado para avaliar a melhor dosagem de coagulantes em Estações de Tratamento de Água (ETA), bem como para comparar a eficiência de diferentes coagulantes no tratamento de águas superficiais. (LEEUWEN, 1997).

O efluente (água residuária) foi cedido por uma empresa de fabricação de materiais cerâmicos, situada no município de São Paulo.

A turbidez do efluente foi determinada com auxílio de um turbidímetro, modelo TB1000 - MARCONI. O pH foi determinado com auxílio de um pHmetro, modelo 230A ORION.

\section{PROCEDIMENTOS}

Inicialmente, foi preparada uma solução aquosa $1 \% \mathrm{~m} / \mathrm{v}$ de aluminato, presente no resíduo, ou cloreto férrico. Em seguida, utilizando-se o equipamento Jar-Test (Figura 2), foram realizados ensaios para avaliar o desempenho desse resíduo como coagulante no tratamento de águas com elevada turbidez. Esses ensaios foram comparados aos ensaios obtidos com cloreto férrico.

Foram adicionados 2,0 L de efluente em cada jarro, e estes foram submetidos à agitação de $300 \mathrm{rpm}$ durante 1 minuto. Nesse momento, foram adicionadas, simultaneamente, as dosagens de aluminato em cada jarro. Os volumes da solução de $1 \%$ de aluminato adicionados foram $0,5,1,0,2,0,5,0,10,0$ e 15,0 mL. Em seguida, a agitação foi reduzida para $70 \mathrm{rpm}$ e o sistema água/coagulante foram agitados durante 15 minutos. Subsequentemente, os jarros permaneceram em decantação por mais 15 
minutos. Findado este tempo, retirou-se uma alíquota de $20,0 \mathrm{~mL}$ de cada jarro, para realizar as medidas de turbidez. Procedimento idêntico foi realizado com o coagulante de referência, cloreto férrico. Os volumes da solução de $1 \%$ de cloreto férrico adicionados foram $0,5,1,0,2,0,5,0,10,0$ e $15,0 \mathrm{~mL}$.

\section{RESULTADOS}

\section{Desempenho dos resíduos de aluminato de sódio como coagulante químico}

$\mathrm{O} \mathrm{pH}$ e a turbidez do efluente foram determinados pelo pHmetro e turbidímetro e os valores medidos foram iguais a 5,8 e 720,0 NTU, respectivamente.

Os resultados do ensaio de Jar Test, utilizando-se a solução de resíduo de aluminato, são apresentados na Tabela 2.

A eficiência do processo foi analisada em relação à redução de turbidez do efluente, conforme apresentado na equação:

$$
\text { \% Eficiência }=((\text { Turbidez inicial }- \text { Turbidez final }) / \text { Turbidez inicial }) * 100
$$

Figura 2. Equipamento Jar Test, constituído por seis jarros, cada um contendo 2,0 L de efluente.

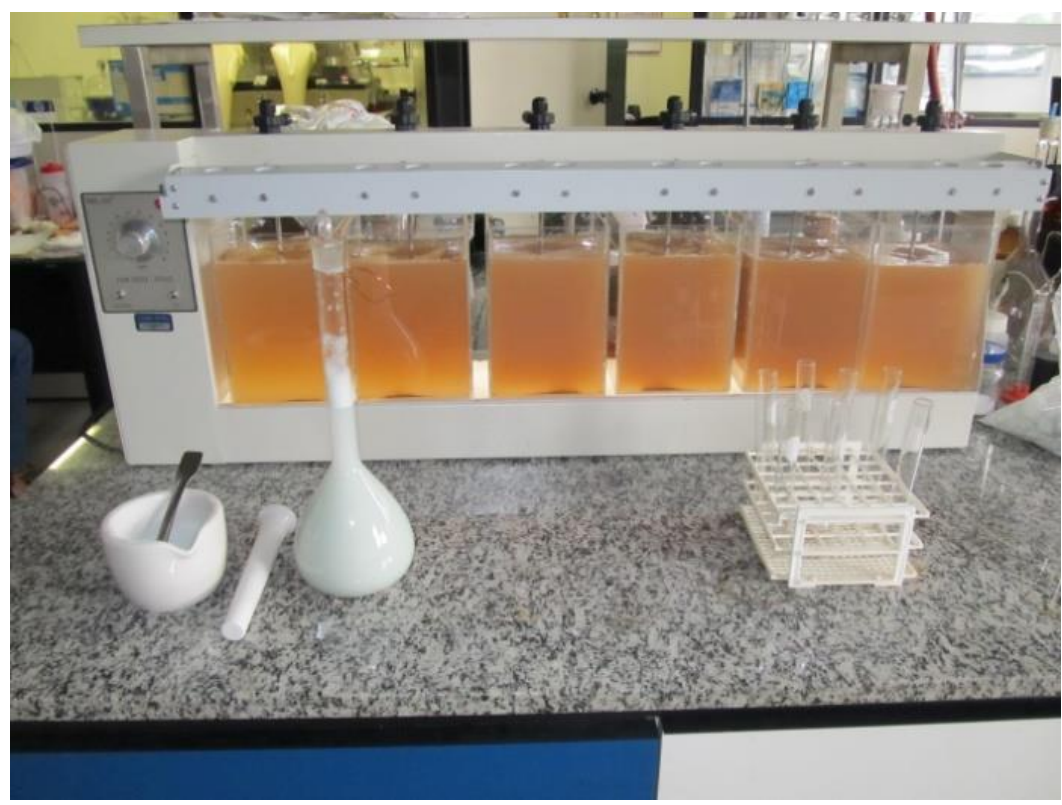

Fonte: Acervo dos autores.

Os resultados apresentados na Tabela 2 indicam que o resíduo de aluminato pode atuar como coagulante no processo de coagulação/floculação, sendo capaz de remover partículas em suspensão na água residuária. 
Tabela 2. Avaliação do desempenho do aluminato para atuar como coagulante.

\begin{tabular}{ccccc}
\hline Jarro & $\begin{array}{c}\text { Concentração de } \\
\text { aluminato } \\
\text { (ppm) }\end{array}$ & $\begin{array}{c}\text { Volume de } \\
\text { aluminato } \\
(\mathbf{m L})\end{array}$ & $\begin{array}{c}\text { Turbidez } \\
\text { final } \\
\text { (NTU) }\end{array}$ & $\begin{array}{c}\text { Eficiência do } \\
\text { processo } \\
(\%)\end{array}$ \\
\hline 1 & 2,5 & 0,5 & 718,0 & 0,3 \\
2 & 5,0 & 1,0 & 715,0 & 0,7 \\
3 & 10,0 & 2,0 & 696,0 & 3,4 \\
4 & 25,0 & 5,0 & 80,9 & 88,7 \\
5 & 50,0 & 10,0 & 59,0 & 91,8 \\
6 & 75,0 & 15,0 & 56,2 & 92,2 \\
\hline
\end{tabular}

A remoção das partículas em suspensão no efluente por meio da adição de aluminato como coagulante também pode ser observada por meio da Figura 3, que apresenta os jarros, após o ensaio do Jar Test.

Figura 3. Equipamento Jar Test, constituído por seis jarros, cada um contendo 2,0 L de efluente tratado com aluminato.

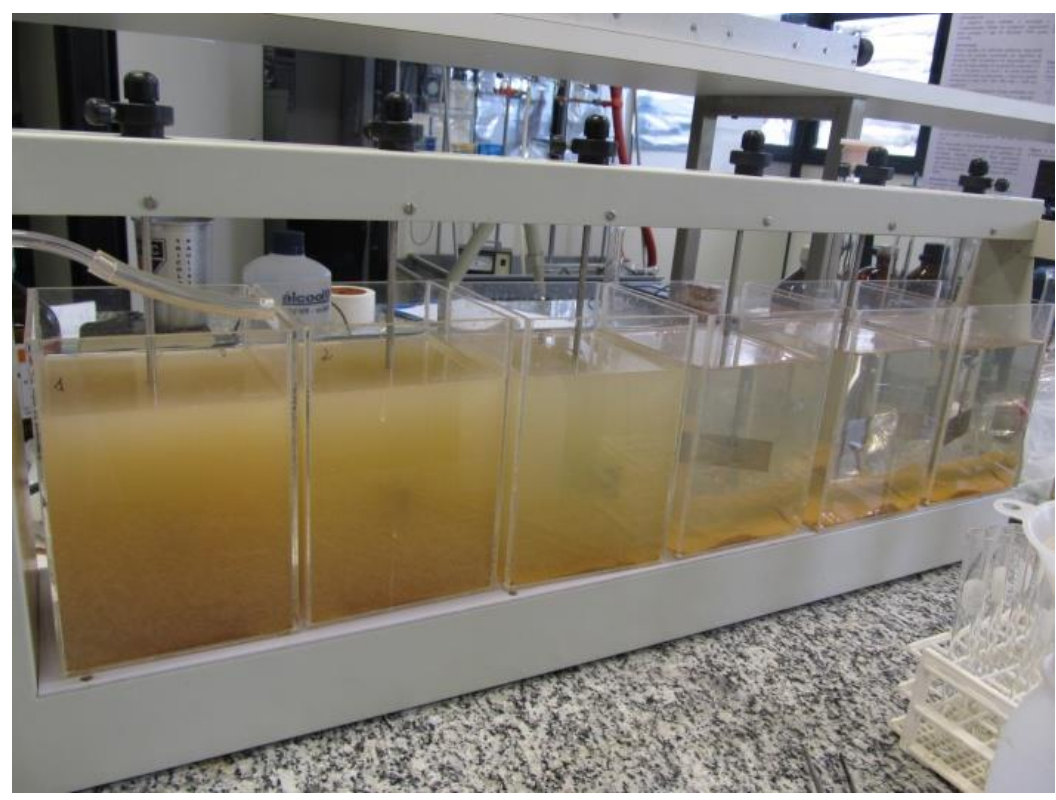

Fonte: Acervo dos autores.

Na Figura 3, foi observada a redução da turbidez da água presente nos jarros, em função da quantidade de coagulante adicionada. Segundo os dados apresentados na Tabela 2, o jarro da esquerda, no qual foi adicionada uma menor quantidade de coagulante, apresenta maior turbidez (718,0 NTU). Vale ressaltar que a adição de aluminato, nas concentrações de 50,0 e 75,0 ppm, foram capazes de remover cerca de $92,0 \%$ das partículas em suspensão no efluente, demonstrando a viabilidade do uso desse resíduo no processo de coagulação/floculação.

A Ficha de Segurança do Produto Químico (FISPQ) indica que devido à sua 
constituição, o resíduo fornecido pela empresa B2Blue, pode provocar danos aos seres humanos, destacando-se queimadura a olhos e pele e irritabilidade às membranas da mucosa, quando inalado. Dessa forma, o resíduo é considerado perigoso e, se descartado de forma inadequada no meio ambiente, pode causar impactos ambientais e riscos à saúde humana. Assim, o reaproveitamento desse resíduo industrial é de fundamental importância.

\section{Ensaios da avaliação da performance do cloreto férrico como coagulante}

Objetivando comparar a eficiência do resíduo aluminato com um coagulante convencional, foram realizados outros ensaios, utilizando o cloreto férrico. Assim, foi preparada uma solução aquosa de cloreto férrico a $1 \%$. Ao término do ensaio, retirouse uma alíquota de $20,0 \mathrm{~mL}$ de cada jarro, para realizar as medidas de turbidez.

A partir dos volumes de cloreto férrico adicionados em cada jarro, foram calculadas as concentrações em ppm e os resultados dos ensaios realizados com o Jar-Test para avaliar a sua melhor dosagem estão apresentados na Tabela 3.

\section{Tabela 3. Avaliação da performance do cloreto férrico para atuar como coagulante.}

\begin{tabular}{|c|c|c|c|c|}
\hline Jarro & $\begin{array}{l}\text { Concentração } \\
\text { de } \mathrm{FeCl}_{3} \\
(\mathrm{ppm})\end{array}$ & $\begin{array}{c}\text { Volume } \\
\text { de } \mathrm{FeCl}_{3} \\
(\mathrm{~mL})\end{array}$ & $\begin{array}{c}\text { Turbidez } \\
\text { (NTU) }\end{array}$ & $\begin{array}{c}\text { Eficiência do } \\
\text { processo } \\
(\%)\end{array}$ \\
\hline 1 & 2,5 & 0,5 & 679,0 & 5,7 \\
\hline 2 & 5,0 & 1,0 & 552,0 & 23,4 \\
\hline 3 & 10,0 & 2,0 & 377,0 & 47,7 \\
\hline 4 & 25,0 & 5,0 & 65,5 & 90,9 \\
\hline 5 & 50,0 & 10,0 & 10,2 & 98,6 \\
\hline 6 & 75,0 & 15,0 & 9,5 & 98,7 \\
\hline
\end{tabular}

Os resultados indicam que, com a adição da solução de cloreto férrico, nas concentrações de 50,0 e 75,0 ppm, correspondentes aos jarros 5 e 6, respectivamente, promove a redução de cerca de $99 \%$ dos sólidos em suspensão presentes na água residuária.

A ação do cloreto férrico como coagulante pode ser observada por meio da Figura 4, que apresenta os jarros após o ensaio.

O cloreto férrico libera íons positivos trivalentes em solução, o que permite a neutralização das cargas negativas das partículas coloidais. Pode ocorrer uma adsorção de compostos hidrolisados do coagulante sobre as superfícies das partículas coloidais, originando pontos em que há possibilidade de ligação entre elas. Esse mecanismo é denominado de coagulação por adsorção-neutralização. (TEIXEIRA, 2013). 
Figura 4. Equipamento Jar Test, contendo efluente tratado com cloreto férrico.

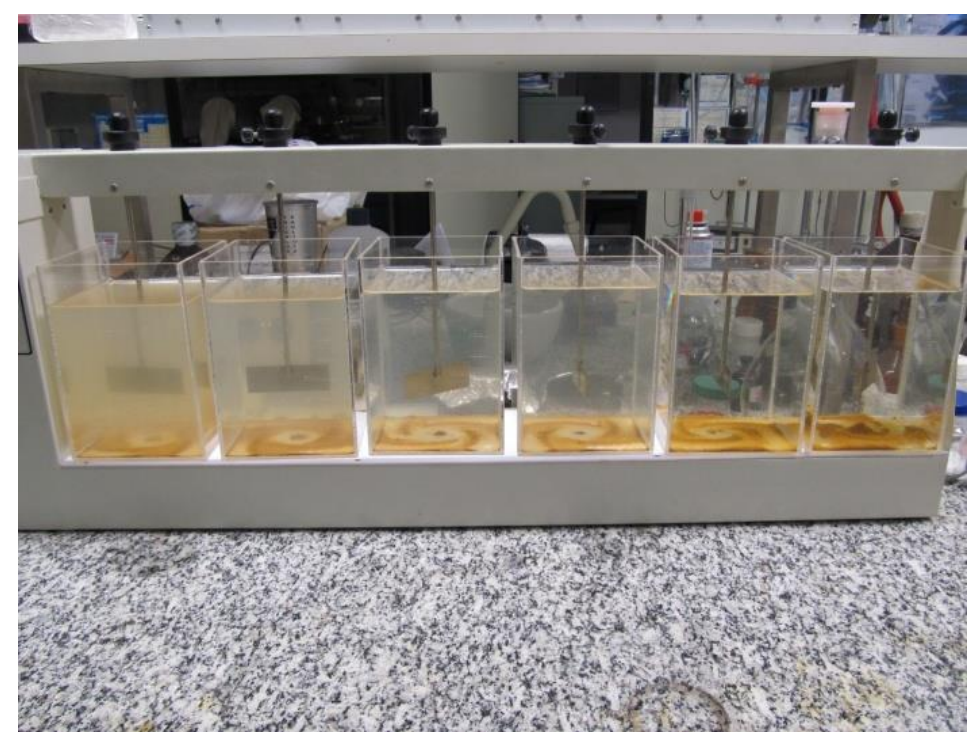

Fonte: Acervo dos autores.

O custo do reagente cloreto férrico da marca Synth, em embalagens de $250 \mathrm{~g}$, é de $\mathrm{R} \$ 34,57$. Por outro lado, no mercado de resíduos, o custo do resíduo de aluminato é de $\mathrm{R} \$ 2,00 / \mathrm{kg}$ (B2Blue, 2014), muito inferior ao custo do coagulante convencional, o que representa vantagem econômica do uso desse resíduo no tratamento de efluentes industriais.

Visando analisar a relação do custo do tratamento de $1,0 \mathrm{~m}^{3}$ do efluente e a redução de turbidez foi elaborado o gráfico da Figura 5. Nesse gráfico, é apresentada uma análise do custo/eficiência do uso dos diferentes coagulantes investigados (cloreto férrico e o resíduo de aluminato). 


\section{Figura 5. Comparação do custo/eficiência para os diferentes coagulantes investigados.}

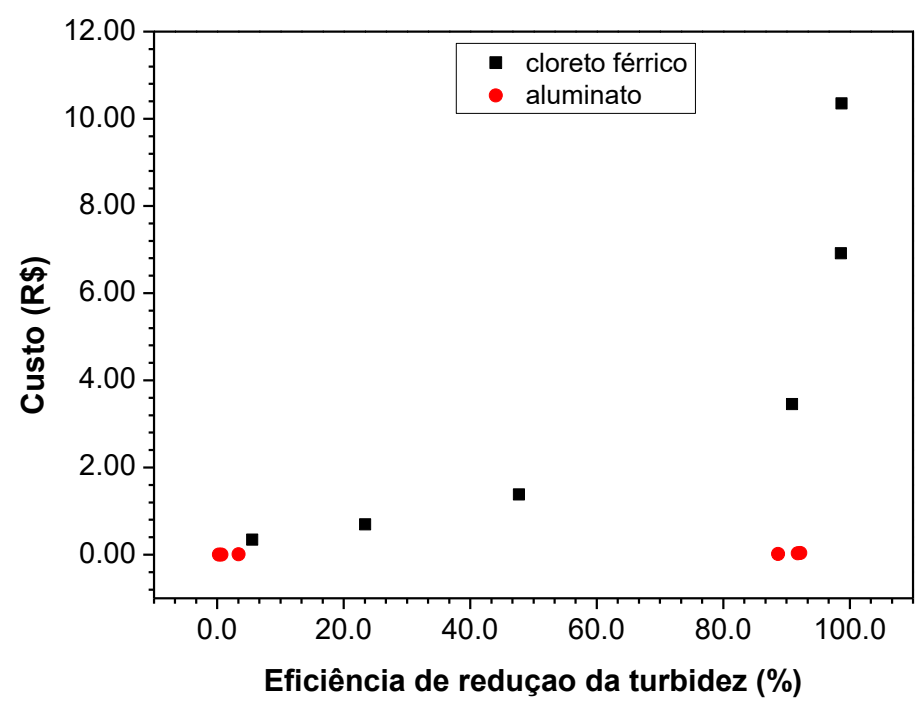

Fonte: Autor.

A adição de 75,0 ppm de aluminato, que corresponde a $15,0 \mathrm{~mL}$ de solução ao efluente, resultou na remoção de cerca de $92 \%$ das partículas em suspensão no efluente. Para tratar $1 \mathrm{~m}^{3}$ do efluente com esse coagulante, o custo seria equivalente a $\mathrm{R} \$ 0,04$.

Por outro lado, para remover, aproximadamente, $91 \%$ de material em suspensão por atuação do coagulante convencional, foi necessária a adição de 25,0 ppm de solução de cloreto férrico, com um custo de $\mathrm{R} \$ 3,45$, para tratamento de $1 \mathrm{~m}^{3}$ do efluente. Dessa forma, pode ser inferido que o uso de resíduos de aluminato no tratamento de águas residuárias pode trazer benefícios econômicos para o setor industrial.

Pode ser ressaltado que o custo para o tratamento do efluente com a adição de 50,0 ppm de cloreto férrico é duas vezes maior, se comparado com a adição de 25,0 ppm. Entretanto, a sua eficiência para remover as partículas em suspensão presentes na água residuária, quando comparado com a adição de 25,0 ppm do coagulante, é apenas 7,8\% maior. Dessa forma, nos ensaios descritos, nos próximos parágrafos, foi fixada a concentração de 25,0 ppm do cloreto férrico.

\section{Ensaios para avaliar desempenho dos resíduos de aluminato de sódio para atuar como coagulante auxiliar no tratamento de águas residuárias.}

Foi analisada a viabilidade do resíduo de aluminato para atuar como coagulante auxiliar no tratamento de águas residuárias. Repetiu-se o ensaio no Jar-Test, adicionando, em cada jarro 2,0 L de efluente, $5,0 \mathrm{~mL}$ de solução de $\mathrm{FeCl}_{3}$ (uma vez que essa dosagem já foi suficiente para a remoção de, aproximadamente, 90,0\% das 
partículas em suspensão) e as dosagens de aluminato indicadas na Tabela 4.

Tabela 4. Avaliação do desempenho do resíduo de aluminato para atuar como um coagulante auxiliar, na presença de $25,0 \mathrm{ppm}$ de $\mathrm{FeCl}_{3}$

\begin{tabular}{cccccc}
\hline Jarro & $\begin{array}{c}\text { Volume } \\
\mathbf{d e} \\
\mathbf{F e C l} 3 \\
(\mathbf{m L})\end{array}$ & $\begin{array}{c}\text { Concentração } \\
\text { de aluminato } \\
(\mathbf{p p m})\end{array}$ & $\begin{array}{c}\text { Volume de } \\
\text { aluminato } \\
(\mathbf{m L})\end{array}$ & $\begin{array}{c}\text { Turbidez } \\
(\mathbf{N T U})\end{array}$ & $\begin{array}{c}\text { Eficiência } \\
\text { do } \\
\text { processo } \\
(\%)\end{array}$ \\
\hline 1 & 5,0 & 10,0 & 1,0 & 51,1 & 92,9 \\
2 & 5,0 & 25,0 & 2,0 & 41,0 & 94,3 \\
3 & 5,0 & 50,0 & 5,0 & 32,4 & 95,5 \\
4 & 5,0 & 75,0 & 10,0 & 18,7 & 97,4 \\
5 & 5,0 & 100,0 & 15,0 & 20,2 & 97,2 \\
6 & 5,0 & 125,0 & 20,0 & 19,4 & 97,3 \\
\hline
\end{tabular}

Os resultados da Tabela 4 mostraram que o melhor desempenho ocorreu quando se adicionou 5,0 $\mathrm{mL}$ de cloreto férrico e 10,0 mL de aluminato de sódio. Nessa condição, foi observada a menor turbidez do efluente tratado.

Comparando-se os resultados das Tabelas 3 e 4, pode ser verificado que a adição de 5,0 mL de cloreto férrico à água residuária gera um efluente com turbidez igual a 65,5 NTU, ao passo que a adição de $5,0 \mathrm{~mL}$ de cloreto férrico $+10,0 \mathrm{~mL}$ de aluminato gera um efluente com turbidez de 18,7 NTU, o que indica que o aluminato pode atuar como um eficiente coagulante auxiliar.

A redução de mais de $70,0 \%$ da turbidez do efluente, quando se adiciona simultaneamente, cloreto férrico / aluminato pode resultar em benefícios ambientais. Segundo a resolução do CONAMA 357/2005, o lançamento de efluentes em corpos hídricos não deve afetar a sua qualidade. A medida de turbidez apresentada por águas naturais depende da sua classificação, águas de classe I, por exemplo, apresentam valores máximos de turbidez até 40,0 NTU, e, portanto, não seria adequado o descarte de efluentes com turbidez de 65,5 NTU.

A remoção das partículas em suspensão no efluente por meio da adição de cloreto férrico e de aluminato pode ser observada por meio da Figura 6, que apresenta os jarros, após o ensaio do Jar Test. 
Figura 6. Equipamento Jar Test, constituído por seis jarros, cada um contendo 2,0 L de efluente tratado com $5,0 \mathrm{~mL}$ cloreto férrico e diferentes dosagens de aluminato.

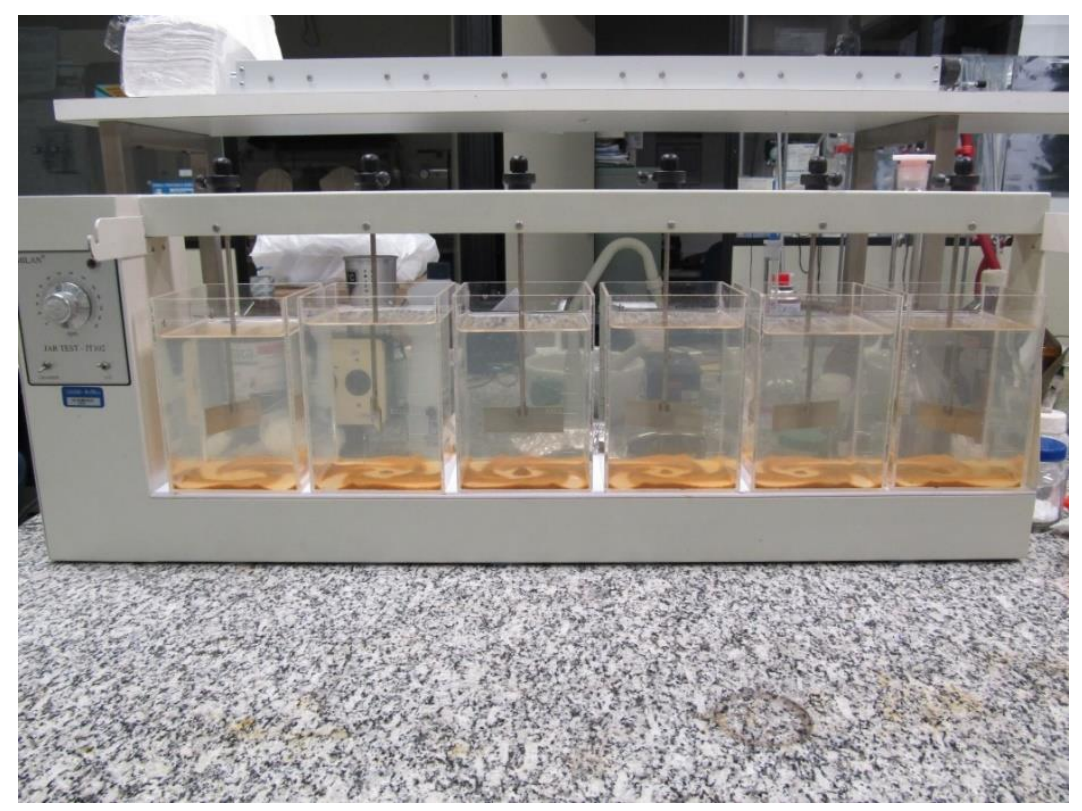

Fonte: Acervo dos autores.

Os resultados apresentados indicam que o resíduo de aluminato pode ser utilizado para o tratamento primário de efluentes industriais, visando à redução da turbidez, de modo que os impactos ambientais sejam minimizados pelo lançamento desses efluentes nos corpos hídricos.

Dessa forma, pode ser inferido que a adição do resíduo de aluminato de sódio reduz a concentração de cloreto férrico a ser utilizado no tratamento do efluente. Vecchia e colaboradores (2012) investigaram a utilização de poliacrilamida aniônica, para atuar como um coagulante auxiliar, o que viabilizou a redução da concentração do sulfato de alumínio utilizado no tratamento de água. Os autores afirmaram que coagulantes auxiliares reduzem a quantidade de lodo gerado em estações de tratamento de água e de efluentes industriais, reduzindo-se custos e elevando a vida útil dos aterros.

Deste modo, a partir do estudo, pode-se deduzir que a redução da concentração do coagulante cloreto férrico, juntamente com o uso de um coagulante auxiliar, o resíduo de aluminato de sódio resulta num menor custo relativo, no tratamento de efluentes.

\section{CONCLUSÃO}

A valoração de resíduos industriais contendo aluminato é importante para evitar o seu descarte no meio ambiente de forma inadequada, o que geraria inúmeros impactos, visto que compostos contendo íons de alumínio causam danos ambientais e à saúde 
humana.

Os resultados apresentados, neste trabalho, permitem concluir que a adição de resíduo de aluminato produz uma eficiente redução da turbidez da água residuária. Foi observado, por meio de ensaios de Jar Test, que a adição simultânea de soluções de cloreto férrico e de resíduo de aluminato, resulta em um efluente com turbidez de, aproximadamente, 20,0 NTU, indicando uma eficiência de remoção de sólidos em suspensão superior a $97 \%$.

Considerando-se o parâmetro turbidez, os resultados sugerem que o efluente tratado ao ser descartado em corpos hídricos não causará os impactos ambientais associados com o lançamento de águas residuárias com elevada turbidez. Dessa forma, pode ser inferido que o resíduo de aluminato é viável para ser utilizado no tratamento primário de águas residuárias.

\section{REFERÊNCIAS}

AMERICAN WATER WORKS ASSOCIATION et al. Coagulation as integrated water treatment process. Journal of the American Water Works Association, p. 72-78, 1989.

BAIRD, C.; CANN, M. Environmental Chemistry. 5. ed. New York: W. H Freeman and Company, 2012.

BRASIL. Lei 12.305, de 2 de agosto de 2010. Dispõe sobre a Política Nacional dos Resíduos Sólidos. Brasília: DOU, 2010. Disponível em: <http://www.planalto.gov.br/ccivil_03/_ato2007-2010/2010/lei//12305.htm> Acesso em: 12 dez. 2014.

BRASIL, CONAMA. Resolução. 357, de 17 de março de 2005. Conselho Nacional do Meio Ambiente-CONAMA, v. 357, 2005. Disponível em:

<http://www.mma.gov.br/port/conama/res/res05/res35705.pdf>. Acesso em: 20 out. 2015.

FREITAS, R.C.S. Tratamento de efluentes oriundos da lavagem de veículos de coleta de resíduos sólidos. Rio de Janeiro, RJ, 2013. 73 f. Dissertação de Mestrado - UFRJ.

LENARDÃO, E. J. et al. Green Chemistry: Os 12 Princípios da Química Verde e sua inserção nas atividades de Ensino e Pesquisa. Química Nova. v. 26, n. 1, p. 123-129, 2003.

LEEUWEN, J. van et al. Comparison of coagulant doses determined using a charge titration unit with a jar test procedure for eight German surface waters. Journal of water supply research and technology-Aqua, v. 46, n. 5, p. 262-273, 1997.

MORUZZI, R.B., SANTOS, J.A.C., GENISELLI, L. Tratamento físico-químico de efluente de indústria cerâmica visando reuso para umidificação da argila. In: USO E REUSO DE ÁGUAS RESIDUAIS, 3, São Paulo, 2009. Workshop..., São Paulo: 
Universidade de São Paulo, 2009.

RIBEIRO, D.M. Resíduos sólidos urbanos no Brasil: impactos e instrumentos adequados de gestão. Revista Eficaz - Revista cientifica online. Paraná, 2010. Disponível em:

<https://www.academia.edu/4874598/REVISTA_EFICAZ_Revista_cient\%C3\%ADfica_ online?auto=download $>$. Acesso em: 10 nov. 2014

SANTOS, G. R. Estudo de Clarificação de Água de Abastecimento Público e Otimização da Estação de Tratamento de Água. Rio de Janeiro, RJ, 2011. $101 \mathrm{f}$. Dissertação de Mestrado - UFRJ.

TEIXEIRA, B.A.N. Coagulação. São Carlos: UFSCar, 2013 [Material didático].

VAZ, Luiz Gustavo de Lima et al. Avaliação da eficiência de diferentes agentes coagulantes na remoção de cor e turbidez em efluente de galvanoplastia. Eclética Química, v. 35, n. 4, p. 45-54, 2010.

DALLA VECCHIA, Paula. Tratamento de água residuária oriunda do processo de lapidação e polimento de vidro. 2012. Trabalho de Conclusão de Curso.

Universidade Tecnológica Federal do Paraná. 